
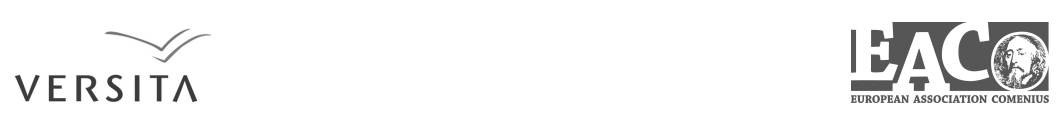

\title{
Tailoring InNovation Policies to Sectors and Regions - The Case of Slovakia
}

\author{
Miroslav Šipikal ${ }^{1}$
}

\begin{abstract}
The aim of the present paper is to investigate channels of innovation and knowledge transfer in the development of the automotive and wood processing sectors in Slovakia and identify suitable policies to support these innovations. We follow the conceptual framework of innovation patterns and try to identify adequate support policies for different regional innovation patterns. We used interviews with several relevant actors in both sectors to identify their innovation activities and the role the external environment plays in them. We found that better functioning support tools in the region are aimed at key channels of knowledge and innovation transfer. We also support the need for a thematically/regionally focused innovation policy approach, as both sectors and regions require different kinds of innovation policies.
\end{abstract}

\section{Keywords}

Innovation, Automotive, Wood Processing, Innovation Patterns, Innovation Policy

\section{Introduction}

Innovation represents a very important part of the growth potential of regions. However, it is very important to support this potential with adequate innovation policies. The INNO Policy Trend Chart 3 currently identifies more than 1,000 horizontal and specific innovation support measures across Europe (PRO INNO, 2009). They are usually oriented towards many different and broad issues such as fostering human capital, supporting R\&D, access to finance, commercialisation of innovation, supporting technology transfer cooperation between universities and foreign investors or adopting a clear and enforceable system of intellectual property rights. Innovation policies in Slovakia are mainly developed on the national level. However, empirical analysis has highlighted the inappropriateness of the “one-size-fits-all” policy (Tödtling and Trippl, 2005). European innovation policies have

${ }^{1}$ University of Economics in Bratislava, Faculty of National Economy, Dolnozemská cesta 1, 85235 Bratislava, Slovak Republic. E-mail: miroslav.sipikal@euba.sk 
to move away from a neutral and generic innovation strategy; they require instead to be based on a thematically and regionally focused innovation policy approach (OECD, 2009; Capello, 2012). The empirical evidence confirms the role of regional specific characteristics in explaining regional innovative activity (Rondé, 2005) and the importance of place in innovation (Barca, 2012; Camagni and Capello, 2013; Matatkova and Stejskal, 2011). The development of a full innovation strategy also requires sectoral understanding and evidence of how innovation happens in the most critical sectors (NESTA, 2007). For example, the latest studies show a difference in the ability of less developed regions to explore the full potential of R\&D (Rodríguez-Pose and Crescenzi, 2008). Regional innovation policy is likely to fail when local strategies deviate considerably from the local context (Lambooy, 2001), implying a need for developing policies targeted at other than only $R \& D$ in order to support innovation in these regions.

This case study supports this selected approach by analysing innovation development patterns and policies in two sectors in Slovakia. The aim of the present paper is to investigate channels of innovation and knowledge transfer in the automotive and wood processing sector development in Slovakia and identify suitable policies to support innovation in these sectors. The case study will show that sectoral and regional characteristics are interconnected and each successful innovation strategy must consider both dimensions. Compared to previous studies, which are based mainly on econometric models or single sector evaluation (e.g. Lengauer et al., 2010), we chose a case study methodology that allowed us to look more closely not only at the existence of channels of knowledge and innovation, but also more specifically at the key elements that influence these channels and also to compare two industry sectors at the same time. Different sectors in different regions rely on different patterns of innovation, so require different strategies to fully exploit their innovation potential. We identify territorial innovation patterns and differences in innovation modes of these sectors. This will lead us to different needs in innovation policy support. We show the importance of fully understanding how historical trajectories affect change in innovation within a particular region.

The paper is organized as follows. In the first part, we describe the methodology of the research. We briefly describe the situation in innovation development in both sectors. In the following section, we analyse existing as well as suitable or suggested support policies to strengthen the innovation performance of the sectors. Finally, we formulate some recommendations for better and more tailored innovation policies.

\section{Methodology}

The methodology of the conducted case studies comes from a conceptual framework of "patterns of innovation". These try to not interpret a single phase of the innovation process, but rather the different modes of performing the different phases of the innovation process, highlighting the context conditions (Capello, 2012). Compared to previous studies, which are based mainly on econometric models, we chose a case study methodology that allowed us to look more closely not only at the existence of channels of knowledge and innovation, but also more specifically at the key elements that influence these channels and suitable policies to support this channels. Our case studies concentrate not on one investment, 
but rather on a single sector, analysing the sector characteristics and the stage of its development in the context of regional innovation.

Data collection is based on quite a large set of in-depth interviews conducted with companies in the sectors, including foreign direct investors, universities, government agencies, research centres and other support institutions at the national and regional levels. We interviewed firms from the whole value chain, from the final producer through to first level suppliers to small local companies at the bottom of the value chain, as seen in Table 1 . Additional information was collected from telephone interviews with some smaller companies in the sector, previous studies in the literature, company websites (namely, their annual reports) and official statistical sources. Furthermore, materials on publicly supported research projects developed by firms, research centres, or universities were collected and consulted.

Table 1: Key interviewed companies

\begin{tabular}{|c|c|c|}
\hline Firm & Key data & Short firm profile \\
\hline A & $\begin{array}{c}\text { Y: } 1993 \\
\text { E: } 1407 \\
\text { T: } 138921\end{array}$ & $\begin{array}{l}\text { Aimed at the production of clutches and torque converters. } \\
\text { The entire research effort is concentrated centrally in the } \\
\text { parent company, process innovation is dominant. }\end{array}$ \\
\hline B & $\begin{array}{c}1996 \\
350 \\
20000\end{array}$ & $\begin{array}{l}\text { Aimed at applied R\&D within the context of the automotive } \\
\text { and engineering industry. Most innovations are carried out as } \\
\text { orders - a client comes with a defined problem which is to be } \\
\text { solved. The firm also executes its own research. }\end{array}$ \\
\hline $\mathrm{C}$ & $\begin{array}{l}1994 \\
650 \\
\text { N/A }\end{array}$ & $\begin{array}{l}\text { Subsidiary company of a multinational corporation with its } \\
\text { central office in the USA and an integrated global manufactu- } \\
\text { rer of engineered structural metal components and assem- } \\
\text { blies. Customer centre also allocated here. }\end{array}$ \\
\hline $\mathrm{D}$ & $\begin{aligned} & 1991 \\
& 8719 \\
& 5373929\end{aligned}$ & $\begin{array}{l}\text { Final car producer of the automotive industry in Slovakia. The } \\
\text { headquarters recently decided to invest another } 300 \text { million } \\
\text { euro in production of new models. }\end{array}$ \\
\hline $\mathrm{F}$ & $\begin{array}{c}2001 \\
650 \\
57489\end{array}$ & $\begin{array}{l}\text { MNC with strong orientation towards export. Allocation into } \\
\text { this area has primarily been performed for supplies for the } \\
\text { VW firm in Bratislava; later on, however, supplies have also } \\
\text { been expanded for other car factories and plants abroad. }\end{array}$ \\
\hline $\mathrm{G}$ & $\begin{array}{c}1993 \\
300 \\
14179\end{array}$ & $\begin{array}{l}\text { Domestic sub-supplier for automotive industry. Innovations } \\
\text { mainly oriented towards the improvement of production pro- } \\
\text { cesses and production efficiency. The firm has used several } \\
\text { supporting programmes aimed at the purchase of technolo- } \\
\text { gies. }\end{array}$ \\
\hline $\mathrm{H}$ & $\begin{array}{c}1995 \\
270 \\
16871\end{array}$ & $\begin{array}{l}\text { Sub-supplier for the automotive industry. This company is } \\
\text { preparing to launch a competence centre which will focus on } \\
\text { research in the field of process automation and new materials. }\end{array}$ \\
\hline
\end{tabular}




\begin{tabular}{|c|c|c|}
\hline Firm & Key data & Short firm profile \\
\hline $\mathbf{J}$ & $\begin{array}{c}1999 \\
25 \\
\text { N/A }\end{array}$ & $\begin{array}{l}\text { Research and development organisation which also carries } \\
\text { out research and development at the order of clients. Strongly } \\
\text { cooperates with the local university. }\end{array}$ \\
\hline K & $\begin{array}{l}2004 \\
20 \\
\text { N/A }\end{array}$ & $\begin{array}{l}\text { Private commercial knowledge-based intensive services com- } \\
\text { pany. Focused mainly on consulting and education in the field } \\
\text { of innovation implementation, innovation management sup- } \\
\text { port and enhancing the efficiency of production processes. }\end{array}$ \\
\hline $\mathrm{L}$ & $\begin{array}{c}1990 \\
1069 \\
112002\end{array}$ & $\begin{array}{l}\text { One of the biggest domestic companies in Slovakia. Also very } \\
\text { active in investment activities abroad. }\end{array}$ \\
\hline $\mathrm{M}$ & $\begin{array}{c}1994 \\
300 \\
36560\end{array}$ & $\begin{array}{l}\text { Foreign-owned subsidiary which is only a production unit for } \\
\text { the mother company. }\end{array}$ \\
\hline $\mathrm{N}$ & $\begin{array}{c}1996 \\
2000 \\
158509\end{array}$ & $\begin{array}{l}\text { Company is a } 100 \% \text { foreign investment, one of the biggest } \\
\text { companies in the wood processing sector in Slovakia, accoun- } \\
\text { ting for more than } 90 \% \text { of exports. }\end{array}$ \\
\hline $\mathrm{O}$ & $\begin{array}{c}2003 \\
120 \\
4000\end{array}$ & $\begin{array}{l}\text { Joint venture of Slovak and foreign capital. Previously a fully } \\
\text { Slovak enterprise which has been able to increase productivity } \\
\text { more than } 40 \% \text { after joint venture creation. }\end{array}$ \\
\hline $\mathrm{P}$ & $\begin{array}{c}1994 \\
300 \\
9062\end{array}$ & $\begin{array}{l}\text { Slovak-owned company with no research, but systematically } \\
\text { able to increase production and export. }\end{array}$ \\
\hline
\end{tabular}

Source: interviews with companies, $Y$-Year of foundation, $E-$ Employment, $R$-revenues, $A-K$ is automotive sector, $L-P$ is wood processing sector

\section{Innovation characteristics of sectors}

The automotive industry is very competitive. The sector is one of the largest private investors in R\&D in the EU (EC, 2009). According to the EU Industrial R\&D Investment Scoreboard, the categories 'automobiles and parts' and 'commercial vehicles and trucks' accounted for $€ 32.8$ billion in R\&D investments in 2008. The actual figure could be even higher, as this category does not include all automotive supplying sectors.

Generally, the automotive sector in Slovakia could be characterized as a creative application pattern (Šipikal and Buček, 2013, see figure 1). Innovation activity within this pattern rests on the merging of external knowledge, coming from networking with leading regions, with local specialized knowledge in the region (Capello, 2013). The present pattern has been developed from a purely imitative pattern in recent years. Especially throughout the 1990s, foreign investors typically began with simple and/or low volume production and only later decided to assign local factories broader and/or more advanced functions within the MNC's production network (Pavlínek et al., 2009). Increased concentration of automotive production in Central and Eastern Europe (CEE) led to increasing external scale economies which improved the competitiveness of CEE-based automotive producers (Pavlínek et al., 
2009). For many companies, several customers and suppliers are concentrated within a "just in time" distance, allowing them to have only a single production plant for them. Innovation implementation was impressively marked by the high portion of FDIs in the sector. Innovation and technological developments at the local level were the result of the passive attitude of the region - in terms of invention, knowledge creation, and innovation generation - which was fed by actors and innovation external to the region (Capello, 2012). Although the key product knowledge and innovation, as well as decisions about their application, are still made outside the Western Slovakia region, some new opportunities have started to open up. This includes increased autonomy for subsidiaries, a shift from defensive strategies associated with lowering costs to offensive strategies associated with assets and knowledge seeking (Hardy, 2011).

Figure 1: Innovation pattern of automotive sector

\begin{tabular}{|c|c|c|c|c|c|c|}
\hline Phases & $\begin{array}{l}\text { Territorial } \\
\text { precondition for } \\
\text { knowledge creation }\end{array}$ & Knowledge output & $\begin{array}{l}\text { Territorial } \\
\text { preconditions for } \\
\text { innovation }\end{array}$ & Innovation & $\begin{array}{l}\text { Territorial } \\
\text { preconditions } \\
\text { for innovation } \\
\text { adaption }\end{array}$ & $\begin{array}{l}\text { Economic } \\
\text { efficiency }\end{array}$ \\
\hline
\end{tabular}

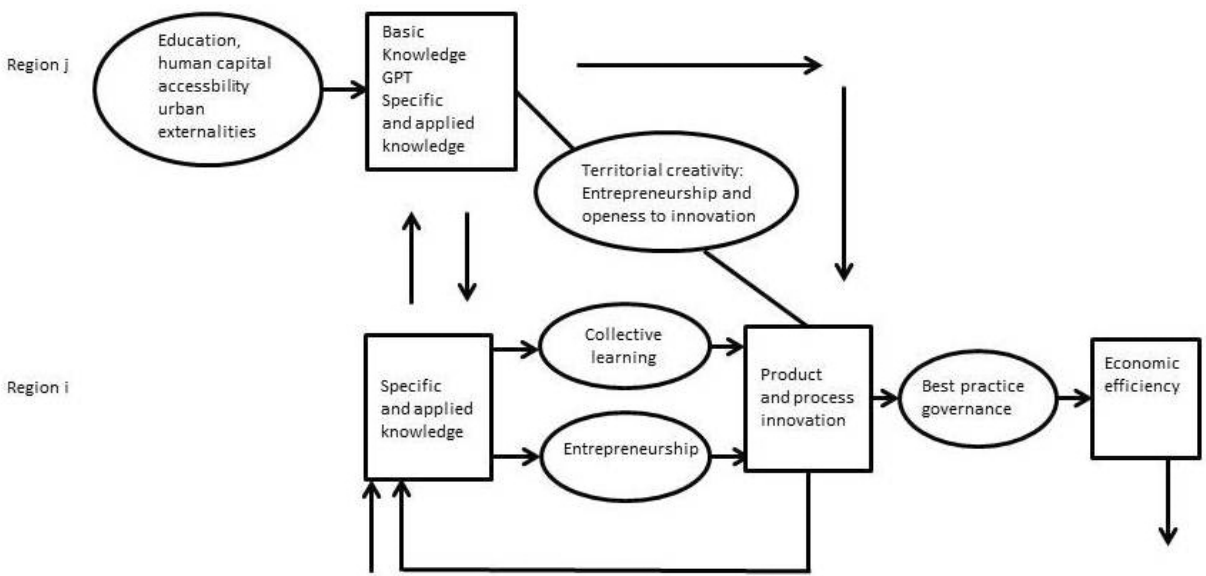

Source: Šipikal and Buček (2013)

Innovation concept, design, and development were key competences of parent companies. The main role of the subsidiaries in this process was implementing these innovations by the most efficient production method. Because of territorial attractiveness in hosting countries, several MNCs started to shift production abroad, while keeping research-related activities in their home countries. However, research also needs experience from the production process, as well as the devices used in production. In fact, many solutions need to be tested and simulated. Because of the relocation of the production stages from the parent companies' countries, firms were forced to transfer a part of their research activities to these production units. This led to the creation of specialised units within the production plants focused on the development of research and innovation. In parallel, employees from those units became members of the research teams of their relative multinational 
companies, thus increasing their ability to conceive and develop innovative solutions. On this, an interviewee reports: "Higher involvement in innovation activities compared to the past is related to the progressive labour force improvement as well as to knowledge acquisition directly from the production process. This shift may mainly be more visible after production cancellation directly in the company head office. The development of new products without a direct possibility to examine some of the items in the production process cannot be fully done in the parent company and, therefore, started to be partly executed in this plant. In the last year, this plant also introduced its own innovations based on its own patent protection solution, which was previously the domain of the parent company. The firm also uses the system of innovatory movement for the moderate improvement of production processes. Tacit knowledge from the direct experience of production process plays a key role."

As an outcome of these processes, strong specialisation in process innovation has been developed in Slovakia (Šipikal and Buček, 2013). This has led to a shift in the innovation pattern from an imitative to creative application pattern, using local knowledge regarding production processes and combining them with product innovation from the external environment (parent companies). This positive evidence of the upgrading of the automotive sector in Central and Eastern Europe is also supported in other studies (Lorentzen et al., 2003; Pavlínek et al., 2009).

On the contrary, the innovation pattern of wood processing sector is still imitative (Capello, 2012), as shown in figure 2. In the absence of local preconditions for knowledge and innovation creation at the local level, innovation results from the passive attitude of a region which is fed by external actors with existing innovations developed elsewhere (Capello and Lenzi, 2013).

Products in the wood processing industry are not very complex. In reference to the furniture production industry, the majority of innovations are about the design and process of production. It is necessary to mention that the wood processing industry is one of the traditional sectors in the region and has a very long history. At the same time, this leads to a strong dependency. A large number of the firms are established in locations where production capacities have existed for several tens of years. The region must therefore tackle the lock-in problem and pay very little attention to the creation of new markets in main or related sectors. Also, foreign direct investments flow into businesses in the region, taking place on the basis of the acquisition of the existing capacities of Slovak businesses. This diametrically differs from the automotive industry, where a major part of investments are "greenfield investments".

A relatively low rate of cooperation exists in the sector. Firms are often interconnected with the external environment rather than within the region. According to discussions with companies, the following explanations could be identified:

- Regional cooperation is not necessary - firms currently acquire innovations primarily from sources situated outside the region. Therefore, it is more important for them to sustain these channels of innovation transfer than to develop local competition; 
- Local competition prevails - in contrast to the automotive industry, decisive competitors are not global players but local companies. Therefore, the creation of a competitive advantage is focused on whichever firm is better able to imitate the newest global innovations in the sector.

A slightly higher rate of cooperation exists with Knowledge Intensive Based Services which are aimed at supporting innovation transfer and education in the field of innovation management and transfer, which is primarily connected with the manner in which firms mainly innovate. At the same time, firms often have contacts or direct links to firms which provide the same services in other regions, where they also have access to the knowledge that businesses in the region overlook.

Innovation activity is usually concentrated only on slight improvement of the product and is much more externally driven than in automotive. As mentioned in an interview with company L:

"A lot of innovations happen because our suppliers of machinery equipment are continually meeting with us to try and show the advantages of new technology. This is very inspiring for us."

This is different from the automotive sector, where the companies themselves are the main drivers of innovation activities and innovation consequently spill over to other sectors. As stated in an interview with a public sector institution:

"Foreign companies were not very interested in cooperation with us. We need to implement several projects that improve our technology and have tried to focus the projects on very specific issues that interested them. This improves our cooperation, but still we see a lot of room for improvement. These projects are very difficult, because MNC are very demanding."

The same is the case for KIBS, as mentioned by them: "We were working on some specific software improvement for FDI in automotive. This required a lot of work from us, but we found out we could now use and offer this knowledge to other sectors, where the companies are not at the level of the requirements."

The wood processing sector indicates a low level of knowledge production and most innovations come directly from external sources or regions. This territorial attractiveness is usually based on cost competitiveness or market seeking (Dunning, 2001) and in this case we could find both cases. The main external sources are machinery suppliers and customers in this sector. 
Figure 2: Innovation pattern of the wood processing sector

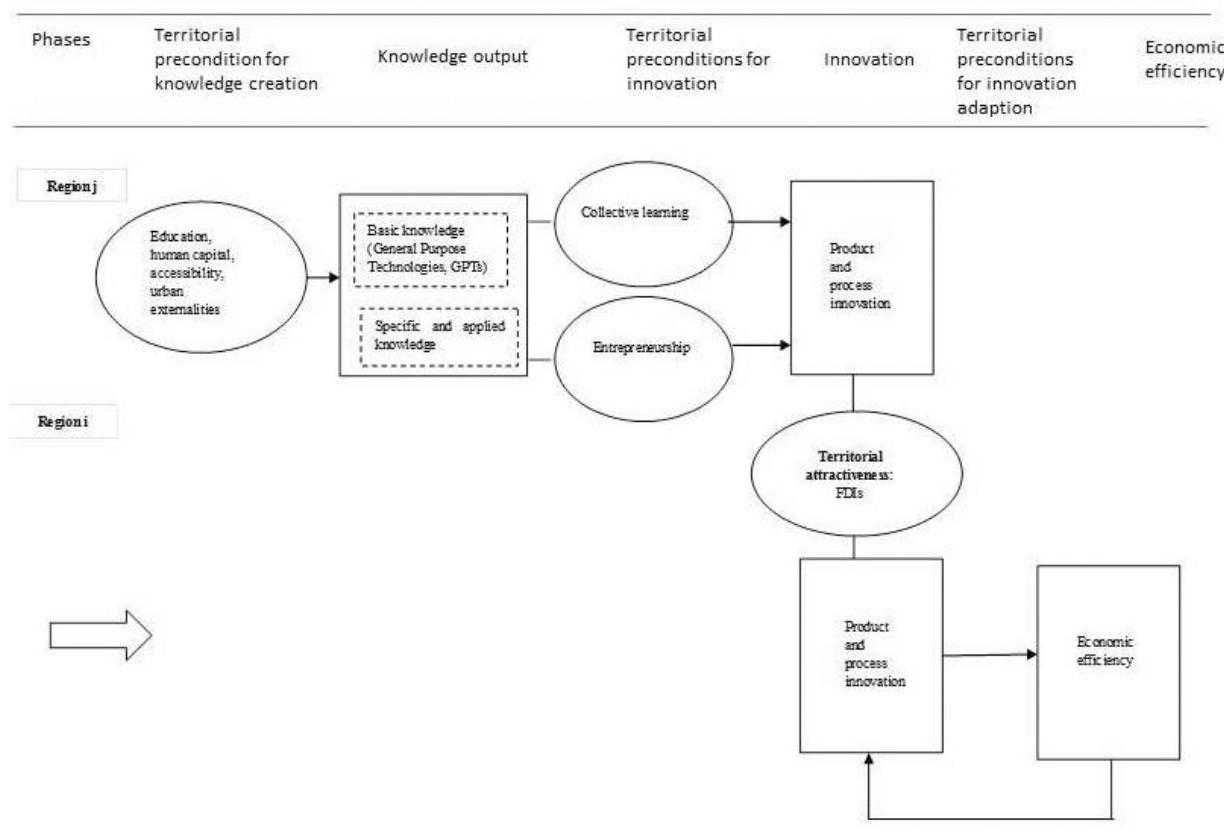

Source: Capello (2012)

As we showed in this section, the innovation activities and requirements in these two sectors are very different. This also leads to a very different perception of their requirements in terms of innovation support policy.

\section{Innovation Policies}

Several different types of innovation policies have been used in Central and Eastern Europe related to innovation and growth promotion (Šipikal et al., 2010). These policies are mainly implemented on the national level and with basically no differentiation between sectors in Slovakia. This type of support is much easier, because sectoral and regional approach requires adequate analysis of each sector, its agents and catalysts and the manner of knowledge and innovation creation and acquisition. However, as we showed in sector development, the innovation needs of the sectors are very different. In the automotive industry, support was mainly in the form of investment stimuli. Only three assembly firms (PSA, VW, and KIA) benefited during their existence from 720 million euro of state aid. Additional financial support was made available to foreign suppliers which followed those MNCs. This support was mainly in the form of a tax holiday and grants for newly-created work positions provided by the national government. The necessary infrastructure was also built with the support of national or regional governments. This aid was, however, oriented more towards the support of regional attractiveness than the support of innovation advances. Several studies consider the role of public policies in 
this respect as rather limited (Rama, 2008). FDI promotion programmes are very often selective and concentrated on particular sectors, placing the government in the position of picking winners and losers better than the market would. However, as reported by Pavlínek et al. (2009), in some cases, such as Slovakia, investment incentives were very aggressive and could quite strongly influence the location of new plants through investment incentives or infrastructure projects. The strong focus on the creation of a critical mass of FDIs rather than a strong orientation towards R\&D foreign investment in the first stages of sector development played a crucial role in the success story of the region. This points to the importance of a close connection between innovation policy and inward investment promotion as development policy tools, two policy areas that have traditionally operated rather separately (Guimon, 2009). This is actually confirmed in the case of the automotive sector.

As mentioned in an interview with $\mathrm{C}$ company:

"At the beginning, we invested there just as market opportunity. Only a few years after the collapse of the soviet bloc, we really were not sure what to expect there and this was related not only to political stability, but also to the quality of the workforce and the business environment. Our Austrian technicians came here every week to set up and control crucial production processes, so we did not even think about research there."

This clearly shows a continuous upgrading of the sectors and a need for different types of support policies at different stages of sector development. The evidence also suggests that R\&D-intensive FDIs occur mainly through the expansion of existing subsidiaries rather than through greenfield investments (Guimon, 2009) and there are only very few such investments in developing or transition (or catching up) countries, such as Slovakia. In fact, there were no direct R\&D-intensive FDIs in the automotive sector in Western Slovakia without previous investment in downstream segments of the value chain. In addition, hidden innovations, as one of the key innovations in the region, are greatly affected by non-innovation policies (NESTA, 2007). Innovation upgrading in the region can to a great extent be achieved by supporting tools of regional policy which are not oriented towards research. This was also the case in Western Slovakia. The FDI attraction policy indirectly had the effect of building up a local knowledge base, by inducing workforce specialisation and upgrading and in turn improving capacities to introduce process innovation. However, this knowledge base was at the early stages totally missing and the direct support of $\mathrm{R} \& \mathrm{D}$ would have been probably misplaced and ineffective. This was also confirmed by several public R\&D projects in the past that brought no long-lasting benefits to regional development. As a result, the successful policy initiatives in the region were those aimed at promoting and supporting key channels of innovation or knowledge inflows in the region. If a region is in the adoptive or imitative innovation pattern (Capello, 2012), efforts centred on the formation of territorial preconditions for knowledge creation are not effective, as no demand for this is locally available. If firms are unable to manage innovation and have no sufficient internal capabilities for using basic research knowledge, there is no reason to actively support the creation of that knowledge. Innovation support in the case of the automotive sector should be oriented towards process innovation, which represents an example of regional specialisation. 
Several interviewees report suggested policy measures to sustain high automotive sector dynamics. Human capital investments could continue to be an effective long-term policy for taking advantage of foreign capital and for favouring linkages creation and knowledge transfer, as also supported by Gentile-Luedecke and Giround (2012). As mentioned in interviews, human capital is one of the key factors for companies to remain. For example, company H said "Our work force represents an important competitiveness factor. Some of them are also becoming important employees for our headquarters", while another mentioned: "We work very hard with employees and their productivity has improved every year. We also contribute to this through strong cooperation with secondary schools."

Much more attention should be given to networking. Cooperation of FDIs in the region with other local public research institutions is limited. Cooperation primarily centres on education and labour force training; more prominent is cooperation with secondary schools and universities. Policies should therefore markedly support the participation of universities and research institutions into international research projects. At present, policies are more oriented towards supporting domestic research, although this does not force universities to progress sufficiently. The establishment of a strong public sector is especially a basic precondition for a further shift of the region towards a knowledge creation pattern. This is consistent with many studies pointing out the importance of stimulating linkages of foreign subsidiaries with local firms, universities, or research centres (Kennel, 2007; Guimon, 2009). Support policies that are concurrently aimed at more subjects seem to be more effective than innovation policies aimed at one subject only. National or regional governments responsible for the support of such policies do not have sufficiently qualified employees who are able to fully understand the contribution of proposed innovation projects to regional development. As a result, a lot of individual innovation projects were supported which had no positive influence on the improvement of regional capabilities for innovation or knowledge creation or acquisitions. The main reason for this is that innovation support for one subject represents only innovation for that subject and in many cases does not represent any innovation for the specific region (Šipikal, 2011). Institutions to evaluate projects do not have staff qualified to assess the difference between innovation related only to enterprise itself and innovation with impact for the region. Those projects which focus only on the support of the public sector (e.g. research centres) often only lead to the creation of a "cathedral in the desert". Research centres established in this manner usually do not have consumers.

In contrast, most common research projects represented much more substantial progress for the region. At the same time, important ties between businesses and universities (or other research institutions) were created. Supporting these ties is also important for improving the ability of local public institutions to create new knowledge. A large part of the sector is formed by MNCs which are not interested in cooperating with local institutions if not motivated by support programmes. Support from so-called specialised competence centres aimed at research in specialised fields, whose condition is the participation of several institutions from private as well as public sectors, seems to work well. This is consistent with Oughton (2002), which calls for effective broad partnership reflecting the industryuniversity-government network as crucial in determining the success of individual projects. 
In our opinion, this is also connected with the need for the achievement of a critical mass of investments into specialised research in the public sector, whereby this region could perform research in those fields at the international level and would become an equal partner for existing MNCs in the region. This could only be achieved in coordination with national and European innovation policies as well as with other policies.

From the abovementioned suggestions, we can also see an important shift in innovation policies requirements. Most of the proposed measures are no longer related to the support of territorial attractiveness. Increasing demand for policies supporting networking, creativity, and knowledge creation is likely to emerge. This ultimately confirms the theoretical proposition highlighting the need to adjust innovation policies to the present stage of sector and region development.

In the wood processing sector, the situation is different. The sector is less competitive and the level of innovation is far behind the automotive sector. Most of the innovation support activities useful in the automotive sector will not function in this sector. Specifically, orientation towards FDI will not bring as much innovation outcome as in automotive. The currently present FDI companies are not innovation drivers and have very weak links with the domestic sector. Most of the previously used support in innovation in the wood processing industry came from EU structural funds. This support was aimed at technology innovation, but was mostly only used to replace old technology. Some companies consider this support unhelpful. As mentioned by company P:

"If I could decide on this support, I would completely cancel it. It just distorts the competitive environment and does not bring new innovations for the region."

Supporting tools, which the region lacks, but in which firms or supporting institutions are interested, can be summarized in two main areas. First is the support of the development of an innovative culture. It is necessary to support education not only concerning proficiency but more importantly the ability to manage innovations and implement an innovative business culture. This also functions on a commercial basis, when firms in the sector realize the need for systematic work with innovations. Only after the achievement of positive change in innovation perceptions in small- and medium-sized enterprises, would it be possible to effectively support the measures as support of clusters or common development projects. Without the creation of this culture in businesses, these measures were and will be useless, because businesses are not interested in them, as several performed projects showed. As supported by an interview with one of the companies:

"We have started to use an external company to improve innovations in our company. We feel the importance of innovation, but there is no one really responsible for this area. They show us very interesting ideas on how to really understand innovation."

Second is support for the opening of new markets. The region lacks both risk capital and active work by supporting institutions with new ideas and inventions which could, in turn, open new markets or expose existing market gaps. For the most part, such established businesses might change their strong path dependency and create basic centres for the accumulation of experience with innovation, which could lead to the creation of specific regional preconditions for single innovation creation from acquired knowledge. 
In general, concerning the implementation of innovations, systems or measures of cooperation that are concurrently aimed at more subjects seem to be more effective than individual measures aimed at only one subject. The main reason for this is that the innovation support for one subject represents only innovation for that subject, not innovation for the region. Institutions aimed at the support of such projects do not have employees sufficiently qualified to determine the contribution of innovation. On the contrary, mutual projects represent the distinctively higher probability of acquisition or creation of innovation. This fact represents qualitative progress for the region. At the same time, important ties between businesses and universities (or other research institutions) are created. Support from these ties is also important for the improvement of the local abilities of public institutions to create new knowledge. A large part of the sector is formed by multinational companies that are not interested in cooperation with local institutions if not motivated by support programmes. Essentially, support from so-called specialized competence centres aimed at the research of specialized fields, whose condition is the participation of several institutions from the private - as well as the public - sector, seems to work well.

In our opinion, this is also connected to the need for the achievement of a critical amount of investments for specialized research in the public sector. This region could, in those fields, perform research on the multinational level and would become an equal partner to existing multinational companies in the region. In particular, the focus on process application and new materials in the automotive industry seems to be a suitable specialisation.

Particularly important is the active support of talented individuals, who may acquire the capability for knowledge and innovation creation without a formal support system. In this way, they could "open channels" for knowledge creation. In the Bratislava region, several examples can also be found where such individuals managed to invent patent solutions on the basis of which local competitive firms were then established. This support should be aimed mainly at the ability of schools to educate such individuals and give them access to risk capital. Innovation created in that way often represents the very first step and can demonstrate to firms that innovations may be created in that environment. These individuals are often the centre of the entire innovation creation system in less developed regions without established innovation systems. The relationship of this support to risk capital in the region is only slightly developed.

\section{Conclusion}

We also analysed innovation policies that help each sector's development. According to PRO INNO (2009), nearly $80 \%$ of innovation support providers would admit that there is a need to improve the existing support mechanisms, so it is very important to select suitable policies that are actually needed for the development of the sector and region. One of the reasons is a centrally-set innovation support policy.

We pointed out the fact that different sectors require different type of policies. Experience shows that successfully functioning support tools in the region are those aimed at the key channel of innovation or knowledge flow in the region and also those with connected conditions leading to such channels. If the region is in a phase of an adoptive or imitative innovation pattern, support which is centred on the formation of a territorial precondition 
for knowledge creation is not effective. The main reason for this is that there is no buyer for the created support system. It is evident that, if firms are unable to manage innovations and have insufficient abilities to make use of basic research knowledge, there is no sense in actively supporting the formation of that knowledge. An example may have already been mentioned: public research centres which are not directly interconnected with the private sector.

The automotive sector is dominated by FDI and is highly innovative. Support policy should therefore focus primarily on the use of this potential and maximize the involvement of the public sector (in particular) in the global automotive value chain within clear regional specialisation.

In the wood processing sector, increased support technology transfer to small and medium enterprises will probably lead to higher growth effects as well as to a concentration of basic R\&D. In the absence of local preconditions for innovation creation, R\&D support is not an effective strategy. Generally, policy actions should be devoted to achieving the maximum return on imitation (Capello and Lenzi, 2013). In this sector, innovation could be mainly be carried out by opening up new markets abroad and support policies could encourage the very effective transfer of innovation as a source of innovation activity for companies.

In both cases, human capital looks crucial for future growth sustainability and development in these sectors, but in a different manner. In the automotive sector, a highly qualified work force with technical skills will be crucial for continuing specialisation in production process knowledge creation. For the wood processing sector, the education of management about the importance of knowledge and innovation creation will provide the opportunity to move from imitative to creative application innovation pattern.

The policy of supporting innovation should very carefully study the local and global conditions which apply to each important sector in order to properly design adequate policies. These innovation support policies must be created in the context of all other support policies, e.g. education, employment or FDI attraction policies, in order to improve the innovative performance of sectors and regions.

\section{Acknowledgements}

This article was supported by a grant from VEGA No. 1/0093/12 "Effectiveness of EU regional policy in Slovak Republic" and ESPON "Knowledge - Innovation - Territory" project.

\section{References}

Barca, F., McCann, P. and Rodríguez-Pose, A. (2012). The case for Regional Development Intervention: Place based versus place neutral approaches. Journal of Regional Science, 52(1), 134-152.

Camagni, R., Capello, R. (2013). Regional Innovation Patterns and the EU Regional Policy Reform: Toward Smart Innovation Policies, Growth and Change, 44(2), 355-389. 
Capello, R. et al. (2012). Knowledge - Innovation - Territory, Scientific report, ESPON, Milano, ISBN 978-2-919777-11-2.

Capello, R. (2013). Territorial patterns of innovation. In Capello, R., Lenzi, C. (eds). Territorial patterns of innovation: An inquiry on the knowledge economy in European regions. Routledge, Oxford.

Capello, R., Lenzi, C. (2013). Territorial patterns of innovation: a taxonomy of innovative regions in Europe, The Annals of Regional Science, 51, 119-154.

Dunning, J. (2001). The Eclectic (OLI) paradigm of international production: past, present and future. International Journal of the Economics of Business, 8(2), 173-190.

European Communities. (2009). Monitoring Industrial research: EU Industrial R\&D Investment Scoreboard, Luxembourg: Office for Official Publications of the European Communities. ISBN 978-92-79-10051-2.

Gentile-Luedecke, S., Giround, A. (2012). Knowledge Transfer from TNCs and Upgrading of Domestic Firms: The Polish Automotive Sector, World Development, 40(4), 796-807. Guimon, J. (2009). Government strategies to attract R\&D-intensive FDI, Journal of Technology Transfer, 34, 364-379.

Hardy, J., Micek, G., Capik, P. (2011). Upgrading Local Economies in Central and Eastern Europe? The Role of Business Service Foreign Direct Investment in the Knowledge Economy, European Planning Studies, 19(9), 1581-1591.

Kennel, S. J. (2007). Foreign Direct Investment and Local Linkages: An Empirical Investigation, Management International Review, 47(1), 51-77.

Lambooy, J. G., Boschma, R. A. (2001). Evolutionary economics and regional policy. The Annals of Regional Science, 35, 113-131.

Lengauer, L., Nussmüller, Tödtling, F. (2010). Innovation and Knowledge Sourcing in the Vienna ICT, Region Direct, 3(1). 4-33.

Lorentzen, J., Mollgaard, P., Rojec, M. (2003). Host-country absorption of Technology: Evidence from Automotive Supply Network in Eastern Europe. Industry and Innovation, 10(4), 415-432.

OECD. (2009). Regions Matter: Economic Recovery, Innovation and Sustainable Growth. Paris: Organisation for Economic Growth and Development.

Matatkova, K., Stejskal, J. (2011). The Analysis of the Regional Innovation Systems Czech Case, paper presented at 51st ERSA 2011 Congress 30th August-3rd September 2011, Barcelona.

NESTA. (2007). Hidden innovation: How innovation happens in six 'low innovation' sectors. London: NESTA. Retrieved April 11, 2012 from http://www.nesta.org.uk/library/documents/Nesta\%20Report\%20HiD\%20Innov\%20final.pdf.

Oughton, C., Landabaso, M. and Morgan, K. (2002). The regional innovation paradox: innovation policy and industrial policy. Journal of Technology Transfer, 27, 97-110.

Pavlínek, P. et al. (2009). Industrial Upgrading Through Foreign Direct Investment in Central European Automotive Manufacturing. European Urban and Regional Studies, 16(1), 43-63.

PRO INNO. (2009). Making public support for innovation in the EU more effective, Luxembourg: Publications Office of the European Union. 
Rama, R. (2008). Foreign investment innovation: a review of selected policies. Journal of Technology Transfer, 33, 353-363.

Rodríguez-Pose, A., Crescenzi, R. (2008). Research and Development, Spillovers, Innovation Systems, and the Genesis of Regional Growth in Europe. Regional Studies, 42(1), 51-67.

Rondé, P., Hussler, C. (2005). Innovation in regions: What does really matter? Research Policy, 34, 1150-1172.

Šipikal, M. (2011). Strategy of Project Oriented Support of Regional Development in Slovak Republic. Ekonomický časopis, 59(9), 954-968.

Šipikal, M., Buček, M. (2013). The role of FDIs in regional innovation: Evidence from the automotive industry in Western Slovakia. Regional Science Policy \& Practice, 5(4), 475-490.

Šipikal, M., Pisár, P., Uramová, M. (2010). Support of Innovation at Regional Level. $E+M$ Ekonomie a Management, 13(4), 74-84.

Tödtling, F., Trippl, M. (2005). One size fits all? Towards a differentiated regional innovation policy approach. Research Policy, 34, 1023-1209. 